\title{
Optimization of Osmotic Dehydration of Organic Red Pepper Using Response Surface Methodology
}

\author{
Zehra Yildiz $^{a^{*}}$, Ayse Sarımeseli ${ }^{b}$ \\ $\mathrm{a}^{*}$ Department of Energy Systems Engineering, Technology Faculty, Mersin University \\ ${ }^{b}$ Department of Chemical Engineering, Faculty of Engineering, Inonu University
}

Received date: December 2015

Accepted date: January 2016

\begin{abstract}
In the present study, organic red pepper slices were undergone osmotic dehydration process, and response surface methodology (RSM) was used to determine the influence of the process variables. Also, the optimal processing conditions were determined in order to reduce the weight reduction, water loss and solid gain of the red pepper samples to a safe level. A four-level central composite design (CCRD) involving the variables such as temperature $\left(25-45^{\circ} \mathrm{C}\right)$, processing time (30-150 $\left.\mathrm{min}\right)$, salt concentration $(5-25 \%, \mathrm{w} / \mathrm{w})$ and solution to sample ratio $(5: 1-25: 1)$ was developed for this purpose. Data obtained from the RSM was subjected to the analysis of variance (ANOVA) by using a second-order polynomial equation, which provided the optimized process conditions as $34.24{ }^{\circ} \mathrm{C}$ for temperature, 85.94 min for processing time, 5.88\% for salt concentration and 20.79:1 for solution to sample ratio. The weight reduction, water loss and solid gain data were optimized for the osmotic dehydration of pepper slices and the values were found to be $11.40,13.05$ and 0.90 respectively.
\end{abstract}

Keywords: Osmotic dehydration, mass transfer, CCRD, response surface methodology.

\section{Introduction}

Osmotic dehydration is a water removal process by soaking fruits and vegetables in a hypertonic solution such as concentrated sugar syrup, salt or ternary solutions. Two main counter-current flows during osmotic dehydration are the flow of water out of the food into the solution and a simultaneous transfer of solute from the solution into the food. Osmotic dehydration is used as a pretreatment for many processes used to improve nutritional, sensorial and functional properties of food without changing its integrity [1,2]. It is generally applied as a pretreatment before drying processes, and it also increases sugar to acid ratio, and improves texture and stability of pigments during dehydration and storage [3]. It is quite effective at around ambient temperatures, so heat damage to texture, colour and flavour can be minimized [1]. Moreover, osmotic dehydration is proven to be an energy efficient method for the partial dehydration, since there is no need for a phase change. There are various studies available in literature on the osmotic dehydration of vegetables [4-9].

RSM combines mathematics with statistics for designing experiments, building models, evaluating the controlling factors and determining optimum processing conditions. Several factors can be simultaneously varied in this method. The multivariable approach reduces the 


\section{Zehra Yildiz, Ayse Sarımeseli}

number of experiments, improves statistical interpretation possibilities, and evaluates the relative significance of several affecting factors even in the presence of complex interactions. It is usually employed for multiple regression analysis using quantitative data obtained from properly designed experiments to solve multivariable equations simultaneously. There are several works that have been carried out on the optimization of vegetables by using RSM [10-14]. However, no information was found on the statistical modeling of osmotic dehydration of organic red pepper. Hence the present work aimed to model the water loss (WL), solid gain (SG) and weight reduction (WR) as a function of the process variables and to find the optimum operating conditions that maximize WL and WR and minimize the SG using RSM.

\section{Materials and Methods}

\subsection{Materials}

Fresh organic red pepper samples were purchased from a local superstore, then thoroughly washed with water to remove adhering soil and other debris. Then, they were cut into pieces of 1 $\mathrm{cm} \times 1 \mathrm{~cm}$ in thickness. The average moisture content of the samples used was found to be $90.1 \%$ on a wet basis. As the osmotic agent, salt $(\mathrm{NaCl})$ having $99.9 \%$ purity was used. Then osmotic solution was prepared by mixing the salt with a proper amount of distilled water.

\subsection{Experimental Design and Statistical Analysis}

RSM was used to estimate the effects of osmotic dehydration process on WL, WR and SG in organic red pepper slices. A four level central composite design was used by choosing the independent variables as temperature processing time, salt concentrations and solution to sample to ratio. Hence for the generated 30 experiments, RSM was applied to the experimental data obtained by using DX6 Trial software.

\subsection{Experimental Procedure}

The osmotic dehydration experiments were carried out in a $500 \mathrm{ml}$ Erlenmeyer flask, which was placed in a thermostatically controlled water bath shaker. Red pepper samples were cut into small pieces having the dimensions of $1 \mathrm{x} 1 \mathrm{~cm}$ and weighed. They were then placed into dehydrating flasks containing salt solution of varying concentrations $(5-25 \%)$ and the flasks were placed into the water bath that can operate at any desired constant temperature. The solution to sample ratio, on the other hand, was varied between 5:1-25:1. At each sampling time $(0.5-2.5 \mathrm{~h})$, the red pepper slices were taken out of the solution and then gently dried with an adsorbent paper and weighed. The effect of dehydration temperature was also investigated and the experiments were conducted between temperatures of $25-45{ }^{\circ} \mathrm{C}$ for this purpose. The average moisture and dry matter content of the samples were determined by oven drying at $70{ }^{\circ} \mathrm{C}$. All the experiments were done in triplicate and their averages were taken for calculations. Mixing was necessarily made in order to improve mass transfer, to maintain uniform concentration, temperature profile, and also to prevent the formation of a dilute solution film around the samples. Therefore, a mixing speed of $200 \mathrm{rpm}$ was used and maintained constant throughout the study. For an adequate investigation of osmotic dehydration kinetics, individual analysis of each sample was carried out, and WR, SG and WL values were calculated according to the following expressions 


$$
\begin{aligned}
& W R=\left[\left(M_{0}-M\right) / M_{0}\right] \\
& S G=\left[\left(m-m_{0}\right) / M_{0}\right] \\
& W L=W R+S G
\end{aligned}
$$

\section{Response Surface Methodology Modeling}

RSM was used to analyse the controlling process factors and to determine the optimum process parameters for the osmotic dehydration of red pepper. A four-level central composite rotatable design (CCRD) was used for this purpose as mentioned previously. The independent variables were selected as temperature, processing time, salt concentration and solution to sample ratio, and their ranges were chosen as $\left(25-45^{\circ} \mathrm{C}\right),(30-150 \mathrm{~min}),(5-25 \%, \mathrm{w} / \mathrm{w})$ and $(5: 1-25: 1)$ respectively. The dependent variables were WR, SG and WL of the slices. Table 1 shows these independent variables with their codes and actual levels employed in the design matrix. Therefore, second order mathematical models describing the relationships among the processdependent and the independent variables were developed. Coding of the variables was done according to the following equation:

$$
Y=b_{0}+\sum_{i=1}^{k} b_{i} X_{i}+\sum_{i=1}^{k} b_{i j} X_{i}^{2}+\sum_{i j<j}^{k} \sum_{j}^{k} b_{i j} X_{i} X_{j}+e
$$

Quality of the fit of the second-order equation was expressed by the coefficient of determination $\mathrm{R}^{2}$ and its statistical significance was determined by the F-test. The coefficients of the equations were determined by employing DX6 Trial software. Analysis of variance (ANOVA) for the final predictive equation was done using DX6 Trial software. The response surface equation was optimized for desired yields in the range of process variables using DX6 Trial software.

Table 1. Codes and actual levels of the independent variables for design of experiment

\begin{tabular}{lccllll}
\hline \multirow{2}{*}{ Independent Variables } & \multirow{2}{*}{ Symbols } & \multicolumn{5}{c}{ Codes levels } \\
\cline { 3 - 7 } & & -2 & -1 & 0 & 1 & 2 \\
\hline Temperature $\left({ }^{\circ} \mathrm{C}\right)$ & $\mathrm{A}$ & 25 & 30 & 35 & 40 & 45 \\
Processing time $(\mathrm{min})$ & $\mathrm{B}$ & 30 & 60 & 90 & 120 & 150 \\
Salt concentration $(\mathrm{w} / \mathrm{w})$ & $\mathrm{C}$ & $5 \%$ & $10 \%$ & $15 \%$ & $20 \%$ & $25 \%$ \\
Solution to sample ratio $(\% \mathrm{w} / \mathrm{w})$ & $\mathrm{D}$ & $5: 1$ & $10: 1$ & $15: 1$ & $20: 1$ & $25: 1$ \\
\hline
\end{tabular}

\section{Results and Discussions}

\subsection{RSM Modeling}

Results of the different runs of the WR, WL and SG during the osmotic dehydration are shown in Table 2. An analysis of variance (ANOVA) was conducted to determine the significant effects of the process variables on each response. The P-values were used as a tool for checking the significance of each coefficient, which was necessary to understand the patterns of the mutual 


\section{Zehra Yildiz, Ayse Sarımeseli}

interactions between the independent variables. Values of $\mathrm{P}$ less than 0.0001 are the indication of the significant model terms. As can be seen from the table, some process variables were found to be statistically significant for output data at $\mathrm{P}<0.0001$. All process variables had a significant effect on the WR, WL and SG. The corresponding second-order models were assembled for each response as follows

$\mathrm{Y}_{1}=15.19+1.97 \mathrm{~A}+1.89 \mathrm{~B}+2.40 \mathrm{C}-0.20 \mathrm{D}+0.83 \mathrm{~A}^{2}+0.80 \mathrm{~B}^{2}+0.68 \mathrm{C}^{2}+0.27 \mathrm{D}^{2}-0.041 \mathrm{AB}-0.54$ $\mathrm{AC}+0.51 \mathrm{AD}-0.14 \mathrm{BC}-0.57 \mathrm{BD}+0.16 \mathrm{CD}$

$\mathrm{Y}_{2}=16.71+2.13 \mathrm{~A}+2.11 \mathrm{~B}+2.66 \mathrm{C}-0.98 \mathrm{D}+0.89 \mathrm{~A}^{2}+0.84 \mathrm{~B}^{2}+0.74 \mathrm{C}^{2}+0.60 \mathrm{D}^{2}-0.064 \mathrm{AB}-0.64$ $\mathrm{AC}+0.49 \mathrm{AD}-0.21 \mathrm{BC}-0.76 \mathrm{BD}+0.071 \mathrm{CD}$

$\mathrm{Y}_{3}=1.52+0.17 \mathrm{~A}+0.22 \mathrm{~B}+0.26 \mathrm{C}-0.79 \mathrm{D}+0.059 \mathrm{~A}^{2}+0.042 \mathrm{~B}^{2}+0.058 \mathrm{C}^{2}+0.33 \mathrm{D}^{2}-0.023 \mathrm{AB}-$ 0.094 AC-0.026 AD-0.069 BC-0.19 BD-0.093 CD

Results of the experimental studies are also represented in Table 2. Based on the experimental responses, $\mathrm{Y}_{1}$ was produced from the WR data ranged between 9.89 to $24.84, \mathrm{Y}_{2}$ from the data of WL ranged between 10.63 to 26.80 and $\mathrm{Y}_{3}$ from the data of SG ranged from 0.74 to 4.99. Runs 9 and 12 had the maximum and minimum WR, Runs 12 and 24 had the minimum and maximum WL respectively. On the other hand, maximum and minimum SG were obtained from the runs 1 and 12 respectively. The lowest yields of the WR, WL and SG were recorded as 9.89, 10.63 and 0.74 , respectively, and were obtained after the 60th min of the osmotic dehydration process carried out at $30{ }^{\circ} \mathrm{C}$ by using $10 \%$ salt solution and and solution to sample ratio of 20:1. On the other hand, the WR, WL and SG increased to $24.84,26.80$ and 4.99 respectively, when temperature was increased from 30 to $40{ }^{\circ} \mathrm{C}$ with the processing time from 60 to $120 \mathrm{~min}$, salt concentration from 10 to $20 \%(\mathrm{w} / \mathrm{w})$ and solution to sample ratio from 5:1 to 20:1. 
Zehra Yildiz, Ayse Sarımeseli

Table 2. Four-level central composite design and the experimental responses of dependent variables

\begin{tabular}{cllllllr}
\hline No & A & B & C & D & WR & WL & SG \\
\hline 1 & 30.00 & 60.00 & 10.00 & 10.00 & 0.10 & 1.53 & 1.63 \\
2 & 40.00 & 60.00 & 10.00 & 10.00 & 0.15 & 2.20 & 2.35 \\
3 & 30.00 & 120.00 & 10.00 & 10.00 & 0.17 & 2.57 & 2.74 \\
4 & 40.00 & 120.00 & 10.00 & 10.00 & 0.20 & 3.15 & 3.36 \\
5 & 30.00 & 60.00 & 20.00 & 10.00 & 0.17 & 2.60 & 2.77 \\
6 & 40.00 & 60.00 & 20.00 & 10.00 & 0.18 & 2.73 & 2.91 \\
7 & 30.00 & 120.00 & 20.00 & 10.00 & 0.21 & 3.21 & 3.42 \\
8 & 40.00 & 120.00 & 20.00 & 10.00 & 0.22 & 3.38 & 3.59 \\
9 & 30.00 & 60.00 & 10.00 & 20.00 & 0.10 & 0.74 & 0.84 \\
10 & 40.00 & 60.00 & 10.00 & 20.00 & 0.18 & 1.31 & 1.49 \\
11 & 30.00 & 120.00 & 10.00 & 20.00 & 0.14 & 1.05 & 1.20 \\
12 & 40.00 & 120.00 & 10.00 & 20.00 & 0.18 & 1.32 & 1.50 \\
13 & 30.00 & 60.00 & 20.00 & 20.00 & 0.17 & 1.30 & 1.47 \\
14 & 40.00 & 60.00 & 20.00 & 20.00 & 0.19 & 1.45 & 1.64 \\
15 & 30.00 & 120.00 & 20.00 & 20.00 & 0.17 & 1.27 & 1.43 \\
16 & 40.00 & 120.00 & 20.00 & 20.00 & 0.24 & 1.83 & 2.07 \\
17 & 25.00 & 90.00 & 15.00 & 15.00 & 0.14 & 1.56 & 1.75 \\
18 & 45.00 & 90.00 & 15.00 & 15.00 & 0.22 & 2.10 & 2.19 \\
19 & 35.00 & 30.00 & 15.00 & 15.00 & 0.15 & 1.55 & 1.71 \\
20 & 35.00 & 150.00 & 15.00 & 15.00 & 0.20 & 2.02 & 2.21 \\
21 & 35.00 & 90.00 & 5.00 & 15.00 & 0.13 & 1.37 & 1.50 \\
22 & 35.00 & 90.00 & 25.00 & 15.00 & 0.23 & 2.33 & 2.56 \\
23 & 35.00 & 90.00 & 15.00 & 5.00 & 0.17 & 4.99 & 5.15 \\
24 & 35.00 & 90.00 & 15.00 & 25.00 & 0.14 & 0.88 & 1.03 \\
25 & 35.00 & 90.00 & 15.00 & 15.00 & 0.15 & 1.52 & 1.67 \\
26 & 35.00 & 90.00 & 15.00 & 15.00 & 0.15 & 1.54 & 1.67 \\
27 & 35.00 & 90.00 & 15.00 & 15.00 & 0.15 & 1.54 & 1.68 \\
28 & 35.00 & 90.00 & 15.00 & 15.00 & 0.15 & 1.52 & 1.67 \\
29 & 35.00 & 90.00 & 15.00 & 15.00 & 0.15 & 1.51 & 1.69 \\
30 & 35.00 & 90.00 & 15.00 & 15.00 & 0.15 & 1.51 & 1.65 \\
\hline & & & & & & & \\
\hline
\end{tabular}

The ANOVA results of the quadratic regression models for $\mathrm{Y}_{1}, \mathrm{Y}_{2}$ and $\mathrm{Y}_{3}$ are reported in Table 3 . F-values of $12.64,10.67$ and 8.06 for $\mathrm{Y}_{1}, \mathrm{Y}_{2}$ and $\mathrm{Y}_{3}$ imply that the models suggested are significant. Also, the Fisher's F-test with a very low probability value (P-model $>\mathrm{F}=0.0001)$ demonstrates a very high significance for the regression models. The quality of fitting of the models was checked by the determination of $\mathrm{R}^{2}$. Therefore, experimental yields of the fitted second-order polynomial equations were quite well as indicated by high $\mathrm{R}^{2}$ values $(0.9413-$ 0.9702) in Table 3. 
Table 3. Analysis of variance (ANOVA) of the regression parameters for the response surface model for the osmotic dehydration of red pepper

\begin{tabular}{lllllll}
\hline Response & Regression & $\mathrm{df}$ & Sum of squares & $\begin{array}{l}\text { R-square } \\
\left(\mathrm{R}^{2}\right)\end{array}$ & F value & $\operatorname{Pr}>\mathrm{F}$ \\
\hline Weight reduction & Linear & 4 & 0.027 & 0.7774 & 21.83 & $\leq 0.0001$ \\
& Cross-product & 6 & $2.314 \mathrm{E}-003$ & 0.8452 & 1.39 & 0.2707 \\
\multirow{5}{*}{ Water loss } & Quadratic & $\underline{4}$ & $\underline{3.355 \mathrm{E}-003}$ & $\underline{0.9434}$ & $\underline{6.51}$ & $\underline{0.0030}$ \\
& Cubic & 8 & $1.568 \mathrm{E}-003$ & 0.9894 & 3.77 & 0.0485 \\
& Linear & 4 & 18.62 & 0.8037 & 25.58 & $<0.0001$ \\
& Cross-product & 6 & 0.59 & 0.8290 & 0.47 & 0.8229 \\
\multirow{5}{*}{ Solid gain } & Quadratic & $\underline{4}$ & $\underline{3.04}$ & $\underline{0.9600}$ & $\underline{12.28}$ & $\underline{0.0001}$ \\
& Cubic & 8 & 0.82 & 0.9956 & 7.04 & 0.0092 \\
& Linear & 4 & 19.21 & 0.8019 & 25.31 & $<0.0001$ \\
& Cross-product & 6 & 0.64 & 0.8287 & 0.50 & 0.8037 \\
& Quadratic & $\underline{4}$ & $\underline{3.10}$ & $\underline{0.9582}$ & $\underline{11.61}$ & $\underline{0.0002}$ \\
& Cubic & 8 & 0.90 & 0.9959 & 8.11 & 0.0061 \\
\hline
\end{tabular}

The plots of the experimental values of the WR values against the predicted values by Eq. (5) are shown in Fig.1, while the experimental values of WL data against the predicted ones by Eq. (6) and the SG data versus predicted ones by Eq. (7) are shown in Figs. 2 and 3. It is clear that the observed values were in a good agreement with the predicted ones. Hence, a statistically significant multiple regression relationships between the independent variables and the response variables $\left(Y_{1}, Y_{2}\right.$ and $\left.Y_{3}\right)$ were obtained. The second-order polynomial models showed a good fit and effectively represented the relationship among the parameters selected. F- values several times higher than the tabulated ones mean that the model predicted the experimental results quite well and the estimated factors effects were real.

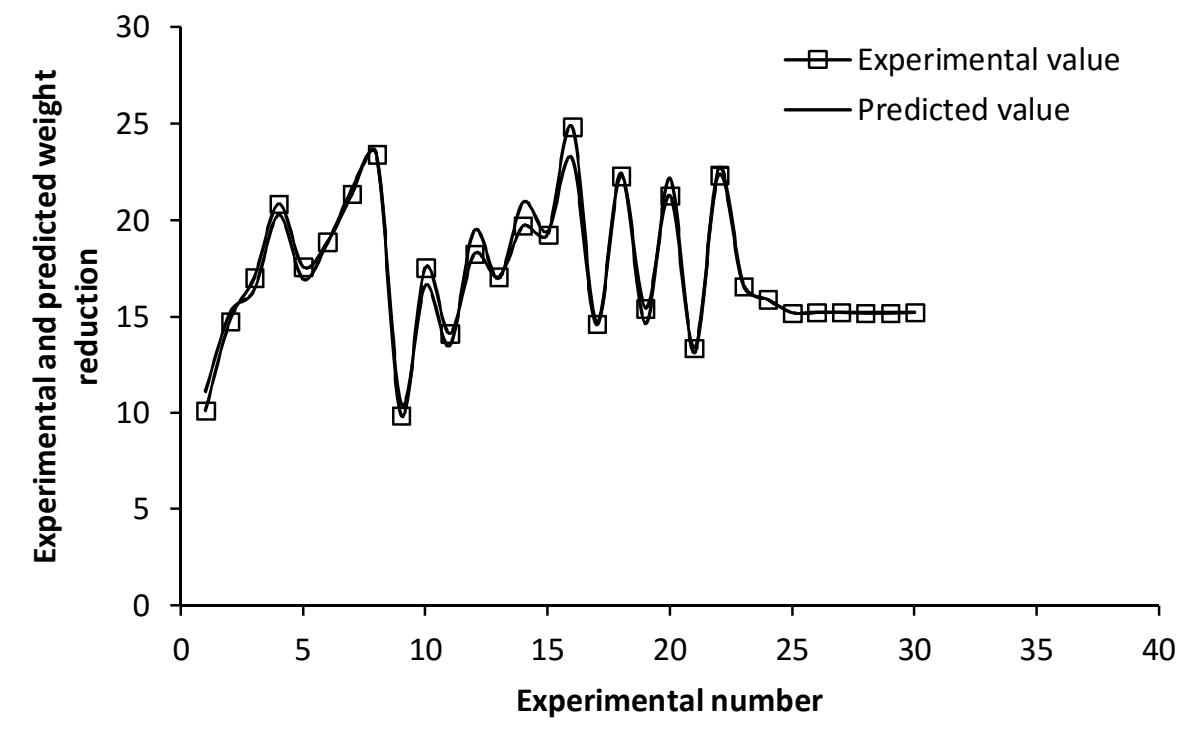

Figure 1: Comparison between experimental and predicted WR on the osmotic dehydration of red pepper 


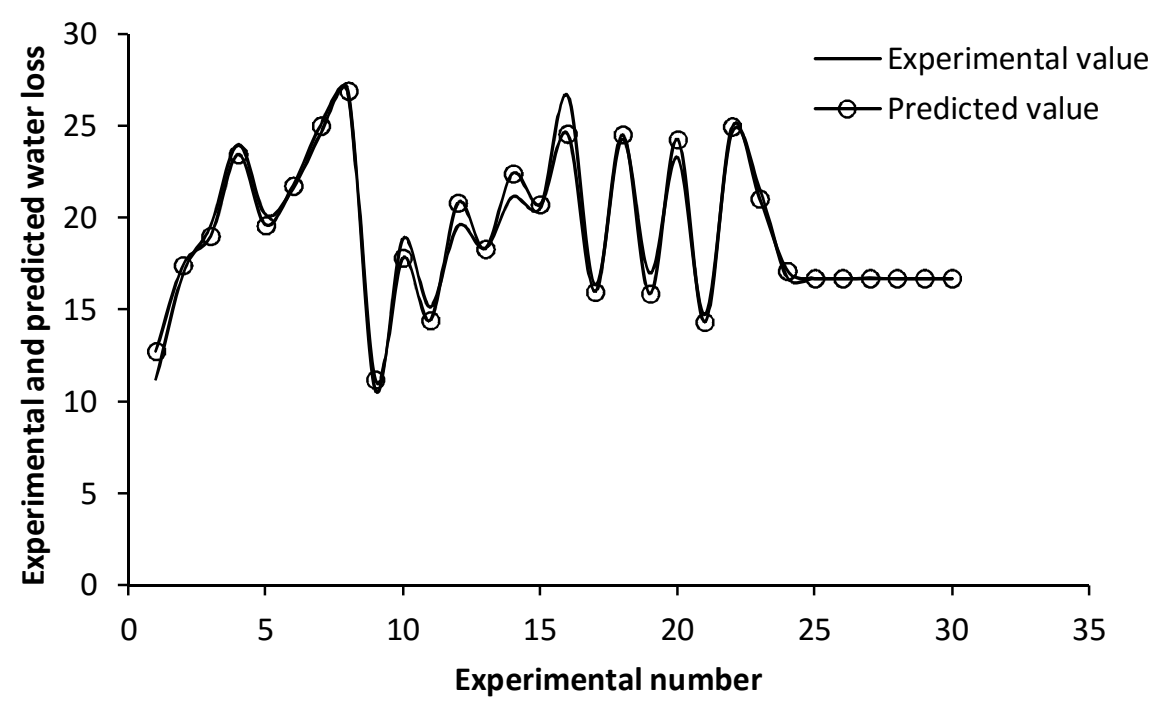

Figure 2: Comparison between experimental and predicted WL on the osmotic dehydration of red pepper

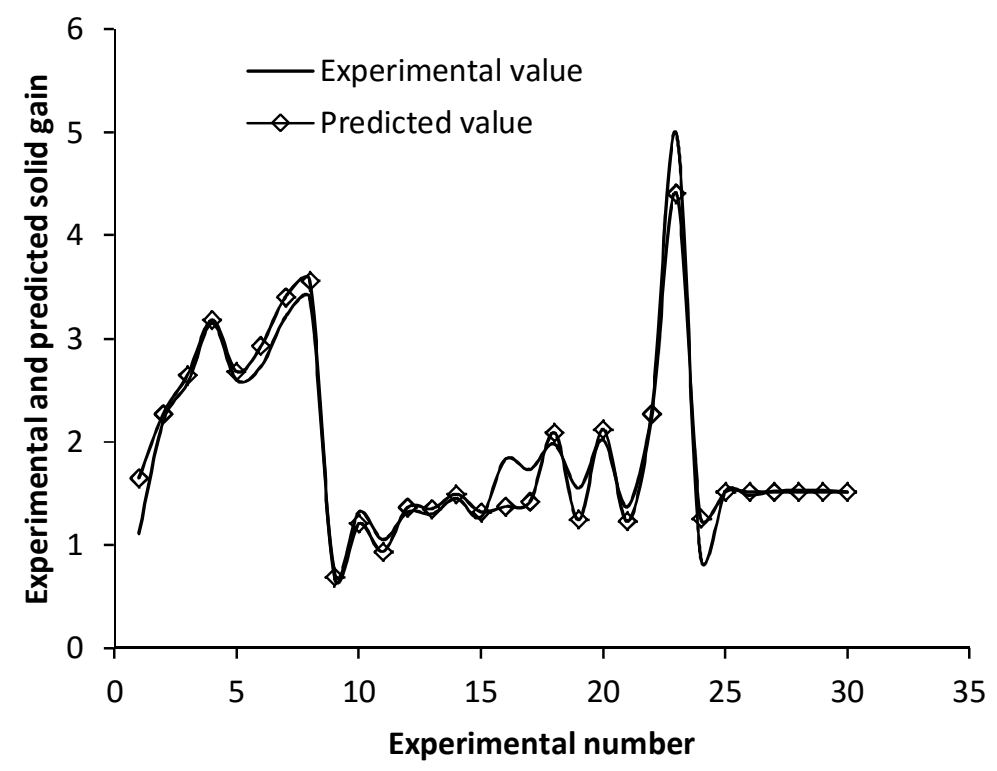

Figure 3: Comparison between experimental and predicted SG on the osmotic dehydration of red pepper. 
The regression coefficients of the $\mathrm{WR}$ model with their corresponding P-values are given in Table 4. It can be deduced that $\mathrm{A}, \mathrm{B}, \mathrm{C}, \mathrm{A}^{2}, \mathrm{~B}^{2}, \mathrm{C}^{2}, \mathrm{AC}, \mathrm{AD}, \mathrm{BD}$ are the significant model terms from these values. The regression coefficients, along with the corresponding $\mathrm{P}$-values, for the model of $\mathrm{WL}$ are presented in Table 5. In this case $\mathrm{A}, \mathrm{B}, \mathrm{C}, \mathrm{D}, \mathrm{A}^{2}, \mathrm{~B}^{2}, \mathrm{C}^{2}, \mathrm{D}^{2}, \mathrm{AC}, \mathrm{BD}$ are the significant model terms. On the other hand, the regression coefficients of solid gain with their corresponding P-values are shown in Table 6. Values of "Prob $>F^{\prime}$ less than 0.0500 indicate that the terms of the model suggested are significant. In this case $A, B, C, D, D^{2}, B D$ are the significant model terms. Therefore, the values higher than 0.1000 indicate that the model terms can be negligible. Analysis of variance (ANOVA) results of the models are shown in Table 3 indicating a good model performance (with a $R^{2}$ value of 0.9702 and a $F$ value of 12.64 for the weight reduction; with a $\mathrm{R}^{2}$ value of 0.9667 and a $F$ value of 10.67 for WL; with an $\mathrm{R}^{2}$ value of 0.9413 and a $\mathrm{F}$ value of 8.06 for solid gain) among linear, quadratic, cross-product, and cubic models. Interactions among the variables were not negligible.

Table 4. Analysis of variance (ANOVA) for the quadratic polynomial model for WR

\begin{tabular}{lllll}
\hline Source & $\begin{array}{l}\text { Coefficient } \\
\text { Estimate }\end{array}$ & $\begin{array}{l}\text { Sum of } \\
\text { Squares }\end{array}$ & $\begin{array}{l}\text { F } \\
\text { Value }\end{array}$ & Prob $>$ F \\
\hline Model & 0.151 & 0.032 & 17.87 & $<0.0001$ \\
$\mathrm{~A}$ & 0.019 & 0.009 & 66.45 & $<0.0001$ \\
$\mathrm{~B}$ & 0.016 & 0.006 & 47.11 & $<0.0001$ \\
$\mathrm{C}$ & 0.022 & 0.012 & 89.82 & $<0.0001$ \\
$\mathrm{D}$ & -0.004 & 0.000 & 2.77 & 0.1171 \\
$\mathrm{~A}^{2}$ & 0.007 & 0.001 & 11.42 & 0.0041 \\
$\mathrm{~B}^{2}$ & 0.006 & 0.001 & 8.25 & 0.0116 \\
$\mathrm{C}^{2}$ & 0.008 & 0.002 & 12.74 & 0.0028 \\
$\mathrm{D}^{2}$ & 0.001 & 0.000 & 0.06 & 0.8045 \\
$\mathrm{AB}$ & 0.000 & 0.000 & 0.00 & 0.9932 \\
$\mathrm{AC}$ & -0.005 & 0.000 & 3.47 & 0.0821 \\
$\mathrm{AD}$ & 0.008 & 0.001 & 7.02 & 0.0182 \\
$\mathrm{BC}$ & -0.002 & 0.000 & 0.58 & 0.4573 \\
$\mathrm{BD}$ & -0.007 & 0.001 & 6.83 & 0.0196 \\
CD & 0.001 & 0.000 & 0.06 & 0.8053 \\
Residual & & 0.002 & & $<0.0001$ \\
Lack of Fit & & 0.002 & 193.41 & \\
Pure Error & & 0.000 & & \\
Cor Total & & 0.034 & & \\
$\mathrm{R}^{2}$ & & 0.9434 & &
\end{tabular}


Table 5. Analysis of variance (ANOVA) for the quadratic polynomial model for WL

\begin{tabular}{lllll}
\hline Source & $\begin{array}{l}\text { Coefficient } \\
\text { Estimate }\end{array}$ & $\begin{array}{l}\text { Sum of } \\
\text { Squares }\end{array}$ & $\begin{array}{l}\text { F } \\
\text { Value }\end{array}$ & Prob $>$ F \\
\hline Model & 1.524 & 22.240 & 25.713 & $<0.0001$ \\
$\mathrm{~A}$ & 0.175 & 0.734 & 11.875 & 0.0036 \\
$\mathrm{~B}$ & 0.202 & 0.977 & 15.812 & 0.0012 \\
$\mathrm{C}$ & 0.242 & 1.409 & 22.814 & 0.0002 \\
$\mathrm{D}$ & -0.804 & 15.498 & 250.860 & $<0.0001$ \\
$\mathrm{~A}^{2}$ & 0.056 & 0.087 & 1.405 & 0.2544 \\
$\mathrm{~B}^{2}$ & 0.045 & 0.055 & 0.894 & 0.3594 \\
$\mathrm{C}^{2}$ & 0.061 & 0.103 & 1.666 & 0.2164 \\
$\mathrm{D}^{2}$ & 0.332 & 3.028 & 49.011 & $<0.0001$ \\
$\mathrm{AB}$ & 0.003 & 0.000 & 0.003 & 0.9606 \\
$\mathrm{AC}$ & -0.067 & 0.071 & 1.150 & 0.3006 \\
$\mathrm{AD}$ & 0.000 & 0.000 & 0.000 & 0.9968 \\
$\mathrm{BC}$ & -0.044 & 0.030 & 0.493 & 0.4934 \\
$\mathrm{BD}$ & -0.162 & 0.417 & 6.755 & 0.0201 \\
CD & -0.065 & 0.068 & 1.094 & 0.3121 \\
Residual & & 0.927 & & \\
Lack of Fit & & 0.925765 & 0.926 & 502.405 \\
Pure Error & & 22.240 & 0.001 & \\
Cor Total & & 23.166 & & \\
$\mathrm{R}^{2}$ & & 0.9600 & & \\
\hline
\end{tabular}

Table 6. Analysis of variance (ANOVA) for the quadratic polynomial model for SG

\begin{tabular}{lllll}
\hline Source & $\begin{array}{l}\text { Coefficient } \\
\text { Estimate }\end{array}$ & $\begin{array}{l}\text { Sum of } \\
\text { Squares }\end{array}$ & $\begin{array}{l}\mathbf{F} \\
\text { Value }\end{array}$ & Prob $>$ F \\
Model & 1.673 & 22.951 & 24.554 & $<0.0001$ \\
$\mathrm{~A}$ & 0.179 & 0.767 & 11.488 & 0.0040 \\
$\mathrm{~B}$ & 0.218 & 1.137 & 17.037 & 0.0009 \\
$\mathrm{C}$ & 0.264 & 1.672 & 25.039 & 0.0002 \\
$\mathrm{D}$ & -0.807 & 15.632 & 234.136 & $<0.0001$ \\
$\mathrm{~A}^{2}$ & 0.055 & 0.084 & 1.262 & 0.2789 \\
$\mathrm{~B}^{2}$ & 0.053 & 0.077 & 1.152 & 0.3001 \\
$\mathrm{C}^{2}$ & 0.071 & 0.138 & 2.062 & 0.1716 \\
$\mathrm{D}^{2}$ & 0.335 & 3.085 & 46.208 & $<0.0001$ \\
$\mathrm{AB}$ & 0.003 & 0.000 & 0.002 & 0.9608 \\
$\mathrm{AC}$ & -0.072 & 0.084 & 1.258 & 0.2796 \\
$\mathrm{AD}$ & 0.008 & 0.001 & 0.014 & 0.9077 \\
$\mathrm{BC}$ & -0.046 & 0.034 & 0.515 & 0.4842 \\
$\mathrm{BD}$ & -0.169 & 0.457 & 6.850 & 0.0194 \\
$\mathrm{CD}$ & -0.064 & 0.065 & 0.976 & 0.3389 \\
Residual & & 1.001 & & \\
Lack of Fit & & 1.000601 & 1.001 & 577.108 \\
Pure Error & & 0.000867 & 0.001 &
\end{tabular}




\begin{tabular}{ll} 
Cor Total & 23.952 \\
$\mathrm{R}^{2}$ & 0.9582 \\
\hline
\end{tabular}

\subsection{Response Surface Analysis of Weight Reduction, Water Loss and Solid Gain Data}

The response surface curves were plotted to understand the interactions between the variables and to determine the optimum level of each variable for maximum response. The curves for WL, SG and WR are shown in Figs. 4-9. The elliptical shape of the curves is an indication of a good interaction, and circular shape is an indication of no interaction between the variables. From these figures, it can be clearly seen that the elliptical nature of the contours in 3D-response surface plots depicts the mutual interactions of all the variables. Also, significant interactions between every two variables, and the presence of the maximum predicted yields as indicated by the surface confined in the smallest ellipse in the contour diagrams were recorded .

The magnitudes of $\mathrm{P}$ and $\mathrm{F}$ values in Table 4 express the maximum positive contributions of temperature, processing time and salt concentration to the WR during osmotic dehydration. They show that WR decreases with decreasing temperature, process time and salt concentration. This is clearly shown in Figs. 4-6. The quadratic terms of temperature, processing time and salt concentration have positive effect on weight reduction. Further, the interactions of A-D and C-D have positive effect, whereas the interactions of A-B, A-C, B-C and B-D have negative effect on WR. The regression coefficients, along with the corresponding P-values, for producing the model of the WR are shown in Table 4. Values of "Prob > F" less than 0.0500 indicate model terms are significant. In this case A-C, A-D, B-D are significant model terms. Values greater than 0.1000 indicate the model terms are insignificant.

The magnitudes of $\mathrm{P}$ and $\mathrm{F}$ values in Table 5 indicate the maximum positive contribution of temperature, processing time and salt concentration, while the negative contribution of solution to sample ratio on the WL during osmotic dehydration. In other words, WL increases with an increase in temperature, processing time and salt concentration up to middle level (level 0 ) and this is clearly depicted in Figures (7-8). The quadratic terms of temperature, processing time and concentration have positive effect and solution to sample ratio have negative effect on WL. Furthermore, the interactions of A-D and C-D have positive effect, whereas the interactions of A$\mathrm{B}, \mathrm{A}-\mathrm{C}, \mathrm{B}-\mathrm{C}$ and B-D have negative effect on WL. Values of "Prob $>$ F" less than 0.0500 indicate model terms are significant. Therefore, A-C and B-D are significant model terms in this case. Values greater than 0.1000 indicate that the model terms can be neglected.

The linear effects of the independent variables show positive contribution on the solid gain, implying that solid gain increased with an increase in three process variables as shown in Fig. 9. The quadratic terms of solution to sample ratio had negative effect on SG, while temperature and salt concentration had positive effect. The interactions of A-B, A-C, B-C, A-D, B-D and C-D had negative effect on SG as shown in Table 6. Again, values of "Prob $>$ F" less than 0.0500 indicated that model terms were significant. In this case B-D were the significant model terms. Values greater than 0.1000 indicate the model terms were negligible. 


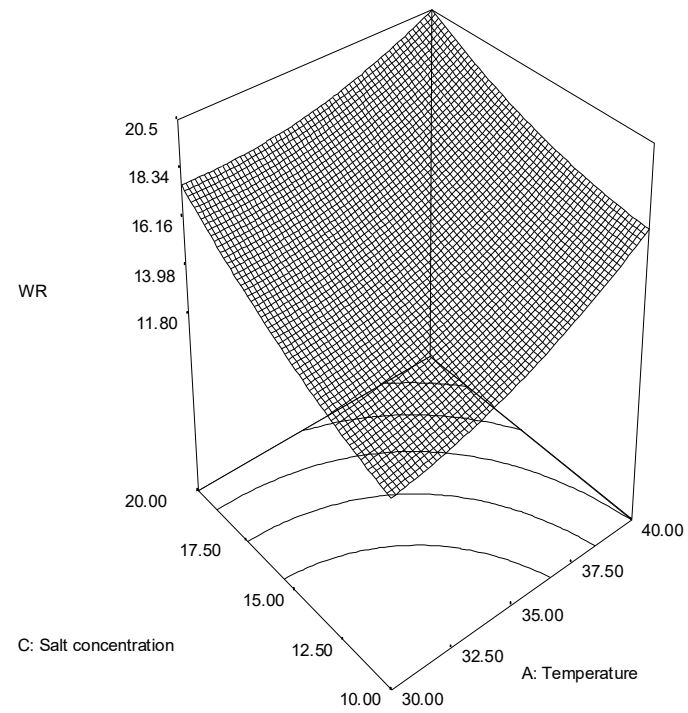

Figure 4: 3D plot of the combined effect of the temperature and salt concentration on WR

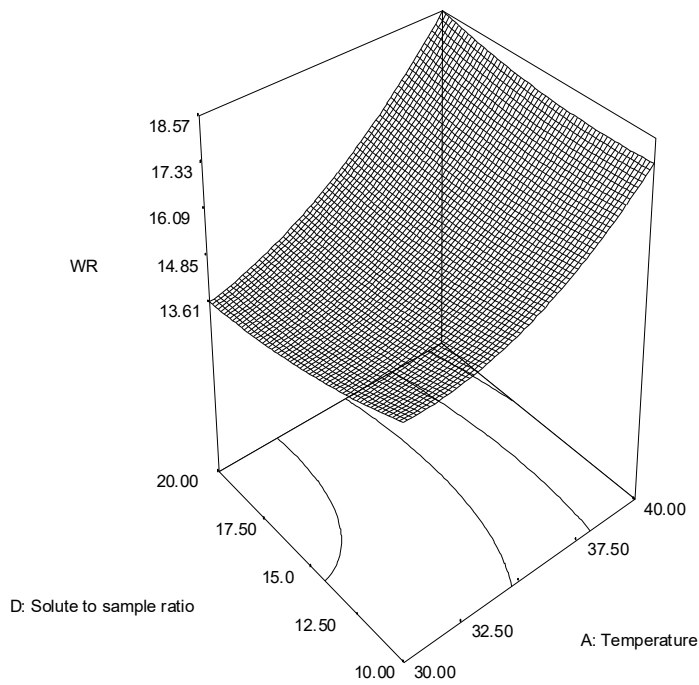

Figure 5: 3D plot of the combined effect of the temperature and solution to sample ratio on WR 


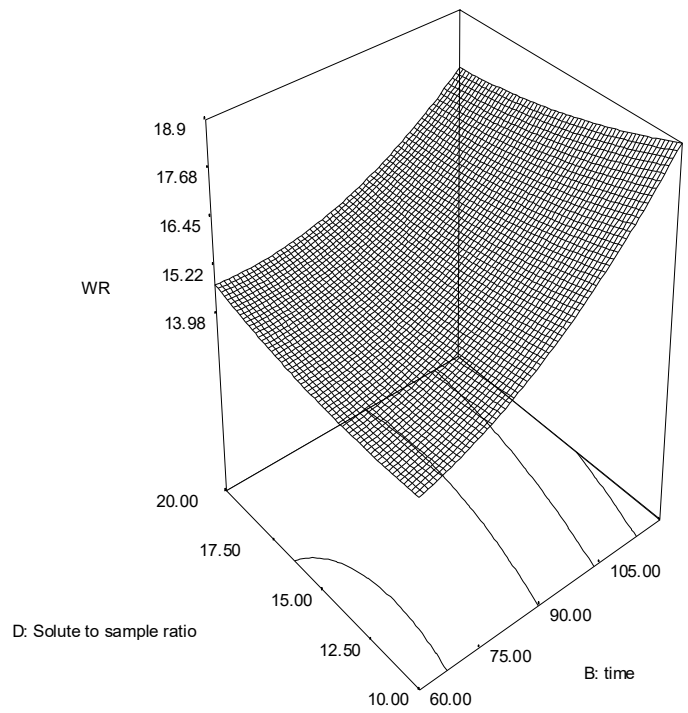

Figure 6: $3 \mathrm{D}$ plot of the combined effect of the processing time and solution to sample ratio on WR

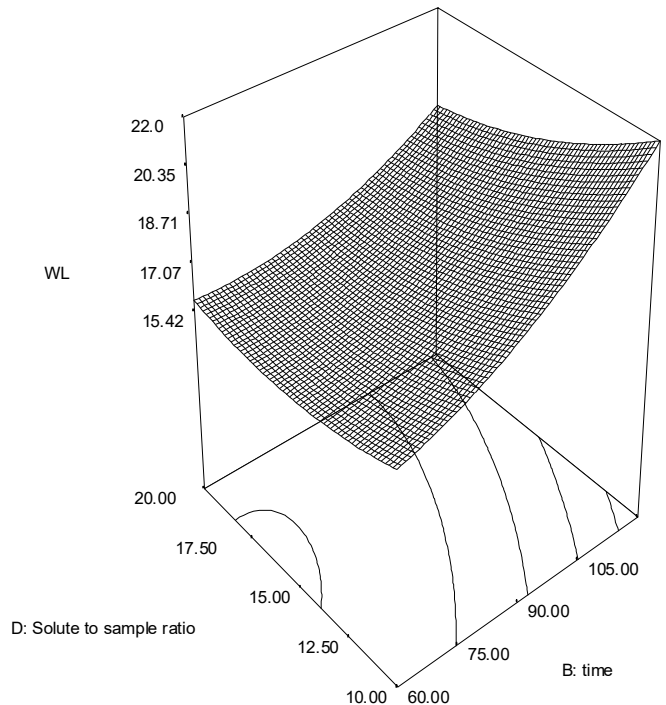

Figure 7: 3D plot of the combined effect of the temperature and salt concentration on WL 


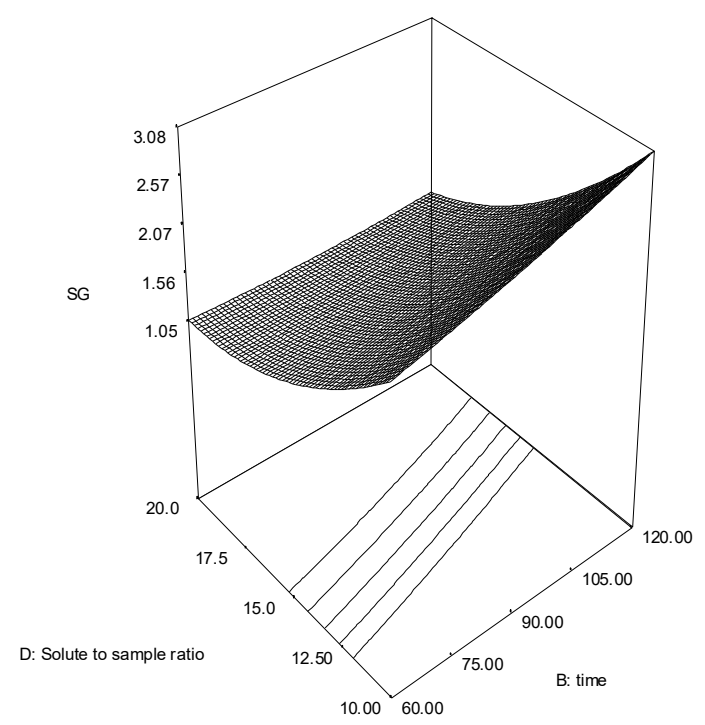

Figure 8: 3D plot of the combined effect of the processing time and solution to sample ratio on WL

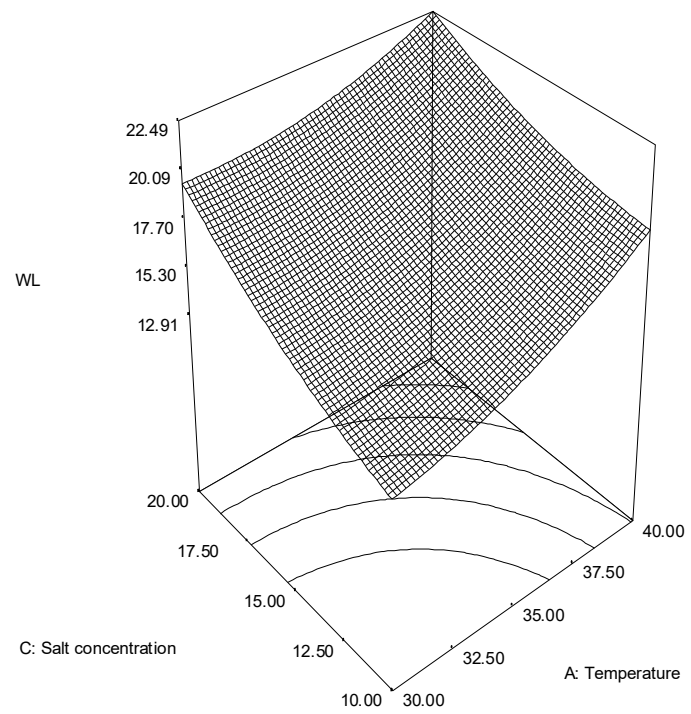

Figure 9: 3D plot of the combined effect of the processing time and solution to sample ratio on SG

\subsection{Optimum Conditions for the Osmotic Dehydration Process}

Investigations of the contour plots given in Figs 4-9 reveal that an optimum region of the process conditions for the osmotic dehydration of red pepper using salt solution exist. Determination of the optimum conditions for the dehydration process of the samples was necessarly made to obtain maximum WL and WR, and minimum SG. Regression models given in Eqs. 5-7 were therefore 


\section{Zehra Yildiz, Ayse Sarımeseli}

used to determine the optimum processing conditions for osmotic dehydration of red pepper. The values of the independent variables were determined, and their responses were calculated at the optimum point. In order to get these optimum values, first the partial derivatives of Eqs. 5-7 were obtained with respect to $\mathrm{A}, \mathrm{B}, \mathrm{C}$ and $\mathrm{D}$ respectively, and they were set to zero to get three equations. Therefore, optimum values of temperature, processing time, salt concentration and solution to sample ratio obtained by substituting the respectively coded values of the variables were calculated as $34.24{ }^{\circ} \mathrm{C}, 85.94 \mathrm{~min}, 5.88 \mathrm{w} / \mathrm{w}$ and $20.79: 1$. Then, at these points, the WL, SG and WR of organic red pepper slices were found as $11.40,13.05$ and 0.90 respectively.

\section{Conclusions}

In this study, RSM was used to determine the optimum operating conditions that would yield maximum WL and WR and minimum SG in the osmotic dehydration of red pepper. Analysis of variance showed that all the process variables including temperature, time, salt concentration and solution to sample ratio were statistically significant. Second order polynomial models were obtained for predicting WL, SG and weight reduction. The optimum conditions were found as the temperature value of $34.24^{\circ} \mathrm{C}$, processing time of $85.94 \mathrm{~min}$, salt concentration of $5.88 \%$ and solution to sample ratio of 20.79:1. Then the corresponding values of WR, WL and SG were found to be $11.40,13.05$ and 0.90 respectively.

\section{Notations}

$\begin{array}{ll}\text { A } & \text { temperature } \\ \mathrm{b} & \text { regression coefficient } \\ \mathrm{B} & \text { processing time } \\ \mathrm{C} & \text { salt concentration } \\ \mathrm{D} & \text { solution to sample ratio } \\ \mathrm{e} & \text { random error. } \\ \mathrm{i}, \mathrm{j} & \text { linear and quadratic coefficients respectively } \\ \mathrm{k} & \text { number of factors studied and optimized in experiments } \\ \mathrm{M} & \text { mass of the sample after dehydration }(\mathrm{g}) \\ \mathrm{m} & \text { mass of the solids in sample after dehydration }(\mathrm{g}) . \\ \mathrm{M}_{0} & \text { initial mass of sample }(\mathrm{g}) \\ \mathrm{m}_{0} & \text { initial mass of the solids in sample }(\mathrm{g}) \\ \mathrm{Y}_{1} & \text { response of weight reduction to independent variables } \\ \mathrm{Y}_{2} & \text { response of water loss to independent variables. } \\ \mathrm{Y}_{1} & \text { response of solid gain to independent variables. }\end{array}$




\section{References}

[1] Torrengiani, D., Osmotic dehydration in fruits and vegetable processing, Food Research International, 26, pp. $59-68,1993$.

[2] Madamba, P. S., Thin layer drying models for osmotically predried young coconut, Drying Technology, 21, pp.1759-1780, 2003.

[3] Raoult-Wack, A.L., Advances in osmotic dehydration, Trends in Food Science Technology, 5, pp.255-260, 1994.

[4] Mudahar, G. S., Toledo, R. T., Floros, J. D. and J. J. Jen, Optimization of carrot dehydration process using response surface methodology, Journal of Food Science, 54, pp.714-719, 1989.

[5] Biswal, R. N., Bozorgmehr, K., Tompkins, F. D. and X. Liu, Osmotic concentration of green beans prior to freezing, Journal of Food Science, 56, pp.1008-1012, 1991.

[6] Rastogi, N. K. and Raghavarao, K.S.M.S., Water and solute diffusion coefficients of carrot as a function of temperature and concentration during osmotic dehydration. Journal of Food Engineering,34, pp.429- 440, 1997.

[7] Kar, A.and Gupta, D.K., Osmotic dehydration characteristics of buton mushrooms, Journal of Food Science Technology, 38, pp.352-357, 2001.

[8] Ade-Omowaye, B.I.O., Rastogi, N.K., Angersbach, A. and Knorr, D., Osmotic dehydration behavior of red paprika (Capsicum annuum L.), J Food Science, 67, pp.1790-1796, 2002.

[9] Sutar, P.P. and Gupta, D.K., Mathematical modeling of mass transfer in osmotic dehydration of onion slices, Journal of Food Engineering, 78, pp. 90-97, 2007.

[10]Uddin, M.B., Ainsworth, P. and Ibanoglu, S., Evaluation of mass exchange during osmotic dehydration of carrots using response surface methodology, J Food Engineering, 65, pp. 473477.

[11]Corzo, O. and Gomez, E.R., Optimization of osmotic dehydration of cantaloupe using desired function methodology, Journal of Food Engineering, 64, pp.213-219, 2004.

[12]Eren, I. and Ertekin, F.K., Optimization of osmotic dehydration of potato using response surface methodology, Journal of Food Engineering, 79, pp.344-352, 2007.

[13] Singh, B., Panesar, P.S., Gupta, A.K. and Kennedy, J.F., Optimization of osmotic dehydration of carrot cubes in sugar-salt solutions using response surface methodology, European Food Research Technology, 225, pp. 157-165, 2007.

[14] Singh, B., Panesar, P.S., Nanda, V. and Bera, M.B., Optimization of Osmotic Dehydration Process of Carrot Cubes in Sodium Chloride Solution, International Journal of Food Engineering, 4, pp.1-24, 2008. 